\section{Incidence of fluorosis and urinary fluoride concentration are not always positively correlated with drinking water fluoride level}

\author{
Arpan Dey Bhowmik ${ }^{1}$, Pallab Shaw ${ }^{1}$, \\ Paritosh Mondal ${ }^{1}$, Chayan Munshi ${ }^{1}$, \\ Swarnak Chatterjee ${ }^{2}$, Shelley Bhattacharya ${ }^{1}$ and \\ Ansuman Chattopadhyay ${ }^{1, *}$ \\ ${ }^{1}$ Department of Zoology, and \\ ${ }^{2}$ Pearson Memorial Hospital, Visva-Bharati, \\ Santiniketan 731235 , India
}

The aim of this study was to assess the effect of fluoride on human health, focusing on the incidence of fluorosis, urinary fluoride concentration and fluoride level in drinking water in three fluoride-affected villages of Birbhum district, West Bengal, India. In one village urinary fluoride concentration was very high along with the occurrence of severe dental and skeletal fluorosis, though fluoride level in drinking water was within the permissible limit. The present study suggests that fluoride intake through other sources is also an important contributing factor in fluorosis, corroborating previous reports on high fluoride contents in crops and vegetables grown in fluoride-affected areas.

Keywords: Dental and skeletal fluorosis, drinking water, fluoride level, urinary fluoride concentration.

FLUORINE, the most electronegative of all elements, is an essential microelement for human health. Due to high electronegativity, it is naturally found in combined form with other elements and rarely occurs in its elemental state. In aqueous solution, fluorine remains as fluoride $\left(\mathrm{F}^{-}\right)^{1}$, and is present in both surface water and groundwater. However, the natural concentration of fluoride in groundwater depends on various factors such as geological, physical and chemical characteristics of the area, soil, porosity of rocks, $\mathrm{pH}$, temperature and depth of the well ${ }^{2}$. Regions with high geothermal or volcanic activity have high fluoride concentration in the environment ${ }^{3}$. In India, higher concentration of fluoride in groundwater is associated with igneous and metamorphic rocks ${ }^{4}$. Anthropogenic activities such as the use of pesticides, fertilizers, sewage and sludges can also amplify the fluoride level in groundwater $^{5-7}$.

The permissible limit of fluoride in drinking water is $1.5 \mathrm{ppm}(\mathrm{mg} / \mathrm{l})^{8}$. Fluoride, at low concentration in drinking water, has beneficial effects on the teeth like prevention of dental caries in children, whereas subjects exposed to a higher concentration of fluoride are reported to suffer from various adverse effects ${ }^{9}$. Absorption of flu-

*For correspondence. (e-mail: chansuman1@gmail.com) oride occurs in both the small intestine and stomach through simple diffusion ${ }^{10}$, and the absorbed fluoride is readily integrated into developing bone and teeth. During tooth development, ameloblast cells of the enamel remain sensitive to fluoride. An adequate amount of fluoride promotes mineralization of enamel and thus prevents dental caries, although higher fluoride intake leads to dental fluorosis ${ }^{11}$. Mild fluorosis is evidenced by opaque patches of chalky-white discolouration of the teeth. In moderate form, brown colouration is observed while severe dental fluorosis is characterized by deep brown colouration with pitting $^{12}$. Chronic fluoride exposure at a higher concentration is associated with formation of skeletal fluorosis, characterized by increased bone mass and density, as well as pain and stiffness in the backbone, hip region and joints $^{13}$. In severe cases, joint movement is markedly reduced in association with crippling deformities of the spine and joints, muscle wasting, neurological defects and compression of the spinal cord. In addition to its effects on hard tissue, fluoride ingestion over a long period of time also affects soft tissues such as liver, kidney, gastrointestinal tract and reproductive organs ${ }^{14}$. Chronic fluoride exposure at high concentration causes detrimental neurological effects ${ }^{15}$, and abnormalities in insulin secretion leading to impaired glucose tolerance ${ }^{16}$. Toxicological studies on murine models revealed that it causes extensive alterations in renal and hepatic histoarchitecture $^{17}$, and was found to be highly genotoxic to mouse bone marrow cells ${ }^{18}$. It is also reported to cause alteration in tissue histoarchitecture and cell cycle in mouse spleen ${ }^{19}$. In zebrafish, fluoride is found to be neurotoxic, affecting its behaviour and leading to alteration in mRNA expression of xenobiotic biomarker genes in brain $^{20}$.

As half of the absorbed fluoride after integration in bone and teeth is excreted through urine ${ }^{21}$, urinary fluoride concentration is recognized as a reliable bioindicator of fluoride exposure in humans ${ }^{22}$, and thus was evaluated in the present study.

The study aimed at evaluating fluoride concentration in drinking water of a fluoride endemic area, followed by assessment of dental and skeletal fluorosis status and urinary fluoride concentration in the population residing there to establish a possible relation among them.

Four adjacent villages, namely Kamdebpur $\left(24^{\circ} 06^{\prime} 32.6^{\prime \prime} \mathrm{N}\right.$, $\left.87^{\circ} 47^{\prime} 28.4^{\prime \prime} \mathrm{E}\right)$, Chalk Atla $\left(24^{\circ} 06^{\prime} 30.1^{\prime \prime} \mathrm{N}, 87^{\circ} 47^{\prime} 23.6^{\prime \prime} \mathrm{E}\right)$, Noapara $\left(24^{\circ} 06^{\prime} 18^{\prime \prime} \mathrm{N}, 87^{\circ} 47^{\prime} 02.2^{\prime \prime} \mathrm{E}\right)$ and Junidpur $\left(24^{\circ} 06^{\prime} 04.6^{\prime \prime} \mathrm{N}, 87^{\circ} 46^{\prime} 54.4^{\prime \prime} \mathrm{E}\right)$ of Rampurhat I Block, Birbhum district, West Bengal, India, were selected. The selected villages are situated in the floodplain of Dwarka river basin, and the study area has extreme temperature conditions in summer and winter. Summer spans over April to June and winter from December to February. Groundwater is the main source of drinking water in these villages. To provide safe (fluoride-free) water, various non-governmental organizations in association 


\section{RESEARCH COMMUNICATIONS}

Table 1. Drinking water fluoride level, urinary fluoride concentration and incidence of dental fluorosis among the affected population

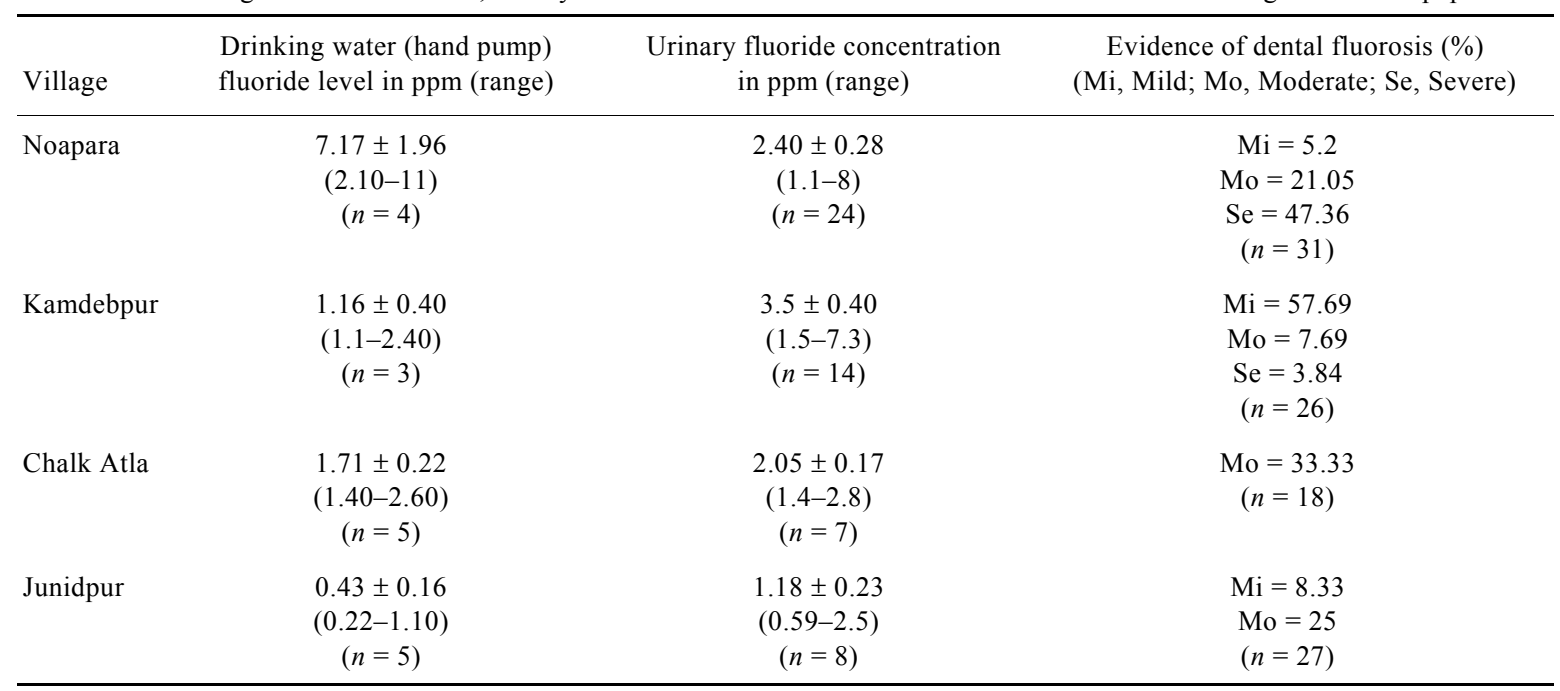

with the local Gram Panchayat supply small-scale filters, but many of them are not in working condition due to lack of periodical maintenance. A large number of villagers are still using hand-pump/tube-well water for drinking purposes. Water samples were also collected from adjacent fluoride-free villages, where no cases of fluorosis have been reported.

A questionnaire having various criteria such as name, sex, address, food habits, health problems, etc. was designed for the survey. Water samples from pond and hand pump, and urine samples were collected in clean, sterilized $50 \mathrm{ml}$ polyethylene tubes. A total of 108 water samples and 80 urine samples were collected for the study. Urine samples were collected with the consent of the subjects. For dental fluorosis, teeth of individuals of different age groups were examined by a qualified dentist following Dean's ${ }^{11}$ classification criteria for dental fluorosis.

Fluoride concentration in water samples was determined electrochemically by an ion selective electrode (Thermo Scientific ORION STAR A214 ISE Meter) using the US EPA ion selective electrode method $^{23,24}$. Standard solutions of 0,1 and $10 \mathrm{ppm}$ fluoride were prepared from the $100 \mathrm{ppm}$ fluoride standard (Orion 940907) for calibration. Urinary fluoride concentration was determined following the method of the National Institute for Occupational Safety and Health (NIOSH) ${ }^{25}$. Fluoride concentration in the samples was determined directly after dilution with equal volumes of total ionic strength adjustment buffer (TISAB) solution $(\mathrm{pH}=5.2$; Orion 940911, Thermo Scientific, USA).

Fluoride concentration in hand-pump water was found to be within the permissible limit $(<1.5 \mathrm{ppm})$ in Kamdebpur and Junidpur, slightly higher in Chalk Atla (1.71 \pm $0.22 \mathrm{ppm})$ and much higher in Noapara (7.17 $\pm 1.96 \mathrm{ppm}$; Table 1). Fluoride level of pond water was within the permissible limit in all the villages. In case-control study, fluoride level of hand-pump water (range 0.03-0.48 ppm) and pond water $(0.16-1.1 \mathrm{ppm})$ in all the villages was within the permissible limit.

The urinary fluoride concentration of individuals not exposed to fluoride was found to be within the range 1.0 $1.5 \mathrm{ppm}$. It was also noted that the urinary concentration in these control subjects varied over different time points selected (1.06 $\pm 0.12 \mathrm{ppm}$ (morning void urine), $1 \pm$ $0.09 \mathrm{ppm}$ (noon), $0.89 \pm 0.12 \mathrm{ppm}$ (night)). Since groundwater is the main source of fluoride in the study area, higher levels of urinary fluoride were considered to be due to chronic exposure to fluoride through drinking water. In subjects of Noapara, exposed to maximum fluoride through drinking water, the urinary fluoride concentration was interestingly found to be similar $(2.40 \pm 0.28)$ to that of individuals residing in Kamdebpur, Chalk Atla and Junidpur $(3.5 \pm 0.40,2.05 \pm 0.17$ and $1.18 \pm 0.23$ respectively), exposed to much less fluoride in drinking water (Table 1).

In Noapara village, $47.36 \%$ of the population surveyed was found to suffer from severe dental fluorosis (Figures $1 e, f$ and 2), much more than in the other three villages. This can be attributed to more fluoride exposure and less fluoride excretion through urine, probably resulting in its deposition and formation of such condition. Also, 52.63\% of the surveyed population was found to suffer from severe pain in the hip, joints and backbone, indicating skeletal fluorosis. The occurrence of mild dental fluorosis was highest $(57.69 \%)$ in Kamdebpur village. The number of fluoride-affected individuals was comparatively less in Chalk Atla and Junidpur. Again, 41.66\% subjects in Junidpur had both hip and joint pain (not severe). Among people in all four villages, $39.13 \%$ suffered from gum-bleeding, $8.69 \%$ had nausea and $19.56 \%$ had abdominal pain. 

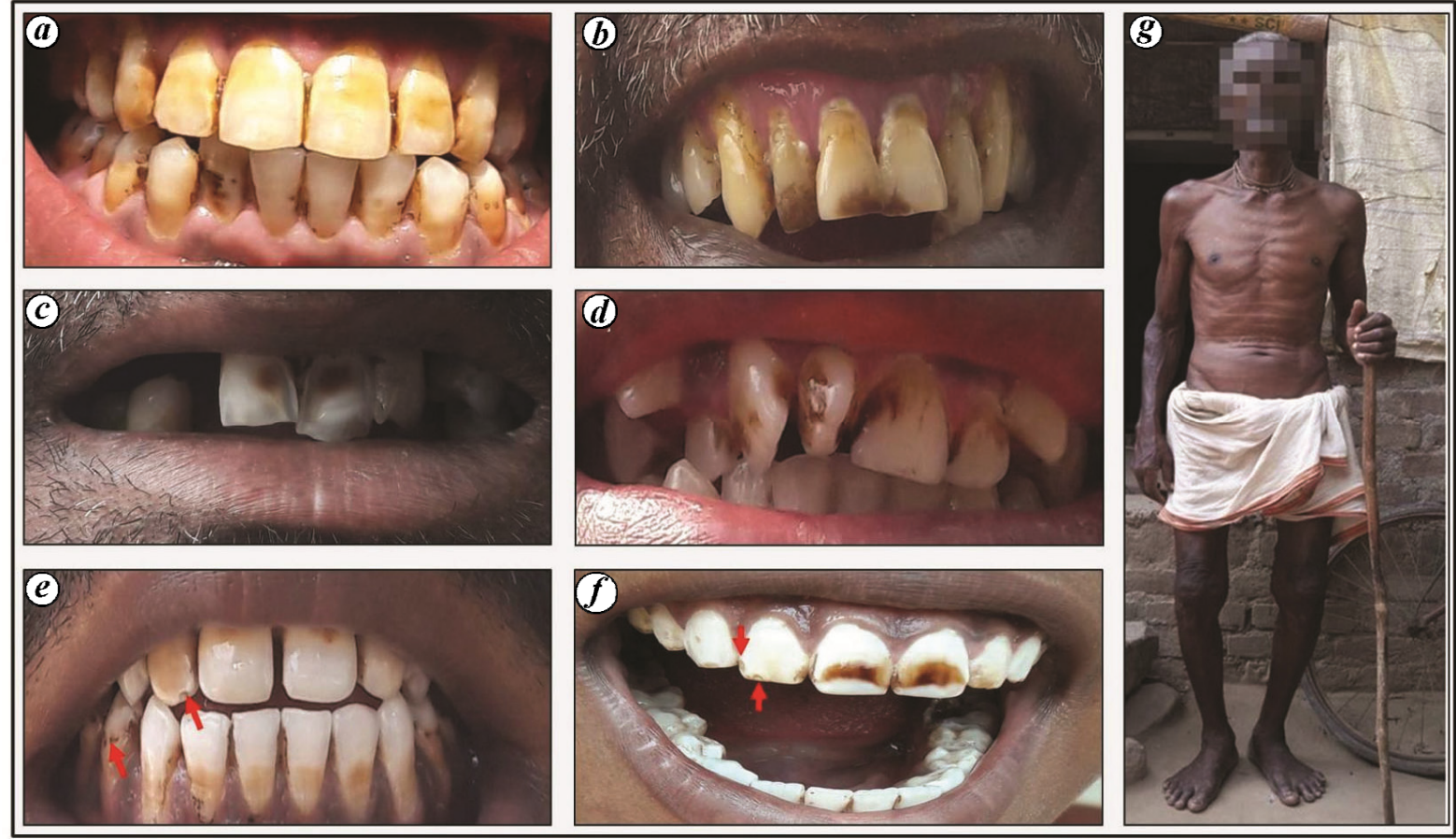

Figure 1. $\boldsymbol{a}-\boldsymbol{d}$, Moderate form of dental fluorosis. $\boldsymbol{e}$ and $\boldsymbol{f}$, Severe form of dental fluorosis (red arrow indicates pitting). $\boldsymbol{g}$, Skeletal fluorosis.

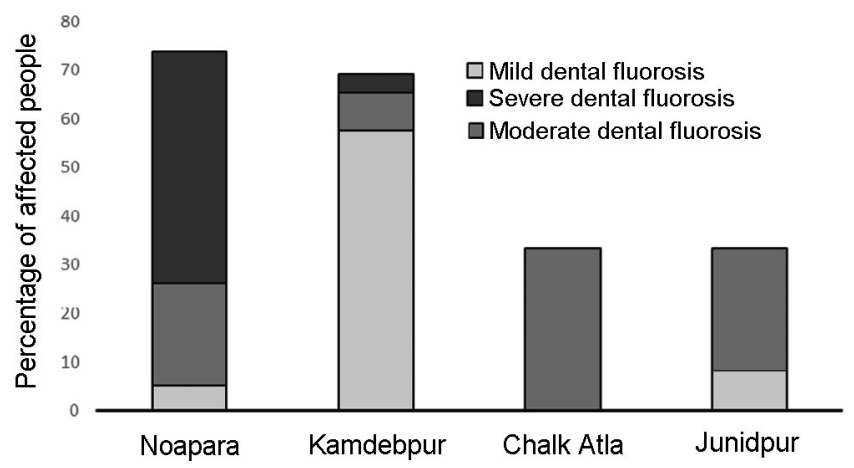

Figure 2. Graph showing the percentage of subjects suffering from dental fluorosis.

Though the concentration of fluoride in drinking water in Noapara was much higher than that in Kamdebpur, Chalk Atla and Junidpur, the urinary fluoride concentration in subjects of Noapara did not differ much. The predominance of severe skeletal and dental fluorosis in subjects of Noapara can probably be linked to high fluoride exposure but relatively less excretion (as evident from urinary fluoride levels). Interestingly, despite low fluoride (within the permissible limit) levels in drinking water, the urinary fluoride concentration of individuals residing in Kamdebpur village was found to be very high (highest $7.3 \mathrm{ppm}$ ). Again, $69.22 \%$ of the people surveyed from Kamdebpur were found to suffer from different forms of dental and skeletal fluorosis (Figure $1 c, d$ and $g$ ). Thus, the evidence of fluorosis and elevated urinary fluoride concentration was not positively correlated with drinking water fluoride level in this sample population. In Junidpur, fluoride concentration in both drinking water and urine was low, but $30 \%$ of the population suffered from mild to moderate dental fluorosis. Data from the present study could not establish a direct correlation between drinking water fluoride level, urinary fluoride concentration and evidence of fluorosis among subjects inhabiting these four fluoride-endemic villages. Therefore, it led us to hypothesize that drinking water may not always be the major source for causing fluorosis. Anasuya and Paranjape ${ }^{26}$ and Tegegne et al. ${ }^{27}$ reported that processing parboiled rice and cooking rice with high fluoride-containing water can increase the level of fluoride significantly. Arora and Bhateja $^{28}$ estimated mean fluoride concentration in the soil, wheat, rice and potato in and around Mathura city to be $1.41,0.39,0.42$ and 
$1.01 \mathrm{ppm}$ respectively. They observed a significant relation between mean fluoride concentration of the soil and mean fluoride concentration of rice and wheat. They concluded that the soil and crops, namely wheat, rice and potato can be an additional dietary source of fluoride. The present study indirectly corroborates these reports showing that not only drinking water, but fluoride intake through food, especially rice, pulses and vegetables might also significantly contribute to the development of fluorosis.

Improving the quality of water supplied and defluoridation of water are major steps necessary to combat fluorosis in fluoride-endemic areas. However, fluoride intake through other food sources and anthropogenic activities, e.g. use of pesticides, fertilizers and coal burning also should be properly monitored, since these might act as significant contributory factors along with fluoridecontaminated drinking water.

Conflict of interest: The authors declare that they have no conflict of interest.

1. Hem, J. D., Study and Interpretation of the Chemical Characteristic of Natural Water, Department of the Interior, US Geological Survey, USA, 1985, vol. 2254.

2. Handa, B. K., Geochemistry and genesis of fluoride-containing ground waters in India. Ground Water, 1975, 13(3), 275-281.

3. Cronin, S. J. and Sharp, D. S., Environmental impacts on health from continuous volcanic activity at Yasur (Tanna) and Ambrym, Vanuatu. Int. J. Environ. Health Res., 2002, 12(2), 109-123.

4. Ramanaiah, S. V., Mohan, S. V., Rajkumar, B. and Sarma, P. N., Monitoring of fluoride concentration in ground water of Prakasham district in India: correlation with physico-chemical parameters. J. Environ. Sci. Eng., 2006, 48(2), 129-134.

5. Datta, P., Deb, D. and Tyagi, S., Stable isotope $\left({ }^{18} \mathrm{O}\right)$ investigations on the processes controlling fluoride contamination of groundwater. J. Contam. Hydrol., 1996, 24(1), 85-96.

6. Patra, R., Dwivedi, S., Bhardwaj, B. and Swarup, D., Industrial fluorosis in cattle and buffalo around Udaipur, India. Sci. Total Environ., 2000, 253(1-3), 145-150.

7. Rao, N. S., The occurrence and behaviour of fluoride in the groundwater of the Lower Vamsadhara River basin, India. Hydrol. Sci. J., 1997, 42(6), 877-892.

8. World Health Organization, Guidelines for Drinking-Water Quality: Recommendations, WHO, Geneva, 2004, vol. 1.

9. Czarnowski, W., Wrzeniowska, K. and Krechniak, J., Fluoride in drinking water and human urine in Northern and Central Poland. Sci. Total Environ., 1996, 191(1-2), 177-184.

10. Whitford, G. M., Intake and metabolism of fluoride. Adv. Dent. Res., 1994, 8(1), 5-14.

11. Dean, H. T., The investigation of physiological effects by the epidemiological method. Fluoride Dent. Health, 1942, 23-31.

12. Fejerskov, O., Manji, F. and Baelum, V., The nature and mechanisms of dental fluorosis in man. J. Dent. Res., 1990, 69(2), 692700 .

13. Boivin, G., Chavassieux, P., Chapuy, M., Baud, C. and Meunier, P., Skeletal fluorosis: histomorphometric analysis of bone changes and bone fluoride content in 29 patients. Bone, 1989, 10(2), 89-99.

14. World Health Organization, Fluorine and Fluorides, WHO, Geneva, 1984.
15. Mullenix, P. J., Denbesten, P. K., Schunior, A. and Kernan, W. J., Neurotoxicity of sodium fluoride in rats. Neurotoxicol. Teratol., 1995, 17(2), 169-177.

16. Trivedi, N., Mithal, A., Gupta, S. K. and Godbole, M. M., Reversible impairment of glucose tolerance in patients with endemic fluorosis. Diabetologia, 1993, 36(9), 826-828.

17. Chattopadhyay, A., Podder, S., Agarwal, S. and Bhattacharya, S., Fluoride-induced histopathology and synthesis of stress protein in liver and kidney of mice. Arch. Toxicol., 2010, 85(4), 327-335.

18. Podder, S., Chattopadhyay, A., Bhattacharya, S. and Ray, M. R., Differential in vivo genotoxic effects of lower and higher concentrations of fluoride in mouse bone marrow cells. Fluoride, 2008, 41(4), 301-307.

19. Podder, S., Chattopadhyay, A., Bhattacharya, S. and Ranjan, R. M., Histopathology and cell cycle alteration in the spleen of mice from low and high doses of sodium fluoride. Fluoride, 2010, 43(4), 237-245.

20. Mukhopadhyay, D., Priya, P. and Chattopadhyay, A., Sodium fluoride affects zebrafish behaviour and alters mRNA expressions of biomarker genes in the brain: role of Nrf2/Keap1. Environ. Toxicol. Pharmacol., 2015, 40(2), 352-359.

21. Cerklewski, F. L., Fluoride bioavailability - nutritional and clinical aspects. Nutr. Res., 1997, 17(5), 907-929.

22. Zober, A., Mallinckrodt, M. G. and Schaller, K. H., Renal fluoride excretion as a useful parameter for monitoring hydrofluoric acidexposed persons. Int. Arch. Occup. Environ. Health, 1977, 40(1), $13-24$.

23. Rum, G., Lee, W. Y. and Gardea-Torresdey, J., Applications of a US EPA-approved method for fluoride determination in an environmental chemistry laboratory: fluoride detection in drinking water. J. Chem. Educ., 2000, 77(12), 1604.

24. Mukhopadhyay, D. and Chattopadhyay, A., Induction of oxidative stress and related transcriptional effects of sodium fluoride in female zebrafish liver. Bull. Environ. Contam. Toxicol., 2014, 93(1), 64-70.

25. Eller, P. M., NIOSH Manual of Analytical Methods (vol. 94), Diane Publishing, 1994.

26. Anasuya, A. and Paranjape, P. K., Effect of parboiling on fluoride content of rice. Fluoride, 1996, 29(4), 193-201.

27. Tegegne, B., Chandravanshi, B. S. and Zewge, F., Fluoride levels in commercially available rice in Ethiopia. Bull. Chem. Soc. Ethiop., 2013, 27(2), 179-189.

28. Arora, G. and Bhateja, S., Estimating the fluoride concentration in soil and crops grown over it in and around Mathura, Uttar Pradesh, India. Am. J. Ethnomed., 2014, 1(1), 36-41.

ACKNOWLEDGEMENTS. We are grateful to all the villagers of the study area and Badal Kumar Konai (Teacher-in-Charge, Chalk Atla Primary School), for their cooperation and support to carry out this survey. Funding: Centre for Advanced Studies (CAS), Phase II programme of University Grant Commission, New Delhi.

Received 13 October 2018; accepted 7 February 2019

doi: $10.18520 / \mathrm{cs} / \mathrm{v} 116 / \mathrm{i} 9 / 1551-1554$ 